\title{
Trabajos de la Universidad de Tübingen en Kom al-Ahmar/Sharuna. La participación del Museu Egipci de Barcelona en el año 2006
}

\author{
Luis Manuel GONZÁLVEZ \\ Cristina BELMONTE \\ Mariángela TAULÉ \\ Farouk GOMAÀ \\ Béatrice HUBER \\ Agustín GAMARRA
}

Desde 1984, el Ägyptologisches Institut de la Universidad de Tübingen ha sido el principal responsable de los trabajos arqueológicos realizados en Kom al-Ahmar/Sharuna. Entre 1984 y 1989, las tareas se centraron en la excavación de las tumbas rupestres del cementerio principal, utilizado sin interrupción desde la dinastía VI hasta la época romana. En años posteriores se excavaron sectores que están ayudando a completar el conocimiento de la historia del yacimiento. Así, en el llamado Kom 'Izba, la utilización del lugar se remonta a comienzos del Reino Antiguo, mientras que iglesias, monasterios e instalaciones de hábitat en tumbas faraónicas reutilizadas, son los principales testimonios relacionados con la ocupación de época bizantina.

En el año 2006 el Museu Egipci de Barcelona, gracias a la gentileza del Dr. Farouk Gomaà, ha participado por primera vez en el proyecto arqueológico de Sharuna, concretamente en la continuación de las tareas de documentación de la necrópolis principal del yacimiento. El trabajo se centró en la definición y la excavación de una tumba de la dinastía VI, parcialmente detectada en campañas anteriores, cuyo sorprendente tamaño (con diferencia, la más grande del yacimiento) no ha permitido ir más allá del patio porticado que precede a la capilla de culto. En dicho patio (de más de $100 \mathrm{~m}^{2}$ ), se han localizado 10 pozos funerarios, la mayor parte contemporáneos a la estructura principal en un primer momento, aunque con diferentes fases de utilización y funciones. Ha resultado también altamente interesante la posibilidad de documentar el aprovechamiento exhaustivo de este patio como zona de hábitat de época bizantina.

Work of the Tübingen University in Kom el-Ahmar/Sharuna. The participation of the Museu Egipci of Barcelona in 2006

Since 1984 the Ägyptologisches Institut of Tübingen University has been principally responsible for archaeological works in Kom al-Ahmar/Sharuna. Between 1984 and 1989, the works were concentrated in the rock tombs of the main cemetery, used without interruption from the VIth dynasty to Roman period. In more recent years sectors have been excavated which are assisting our knowledge of the site. Thus, at Kom 'Izba, the use of the site has been discovered to continue to the beginning of the Roman Empire, whilst churches, monasteries and dwellings in re-used ancient tombs constitute the principal evidence of the Byzantine era.

In 2006, thanks to Dr. Farouk Gomaà, the Egyptian Museum of Barcelona participated for the first time in the archaeological project of Sharuna, specifically in the continuation of the works in the main cemetery of the site. The work concentrated on finding and excavating a VIth dynasty tomb, partially uncovered in previous seasons. Due to its size (the largest in the site), only the court and portico that precede the cult chamber have been excavated. In this court (more than $100 \mathrm{sq}$ metres in area) have been found 10 funerary shafts, most of them contemporaneous to the main tomb. It has been also possible to record the complete adaptation of the court in Byzantine period as a dwelling area.

KEY wORDs: Sharuna / Kom el Ahmar, Old Kingdom, tomb

Fecha de recepción: 16 de enero de 2007

Fecha de admisión: 15 de mayo de 2007

http://doi.org/10.25145/j.TdE.2009.05.01.20 
$\mathrm{K}$ om el-Ahmar Sharuna se encuentra en el Egipto Medio, sobre la orilla oriental del Nilo, a unos $60 \mathrm{~km}$ al norte de Minia y $3 \mathrm{~km}$ al sur del pueblo de Sharuna, topónimo utilizado, junto con el de Suaris, para diferenciar esta área de otras que reciben el apelativo Kom el-Ahmar ("montaña roja") en Egipto.

Sus restos han sido identificados tradicionalmente con la localidad faraónica que las fuentes denominan Hut-nesut ("El Castillo del Rey"). Aunque las menciones escritas no son especialmente abundantes, su nombre está documentado desde finales del Reino Antiguo. A comienzos del Reino Medio, en la Capilla Blanca de Sesostris I figura como capital del nomo XVIII del Alto Egipto, y en época ptolemaica, según la Gran Lista de Edfu, ejerce de ciudad principal del nomo XVII. Otra mención importante ocurre en la Estela de la Victoria de Py, formando parte de la lista de localidades que "abrieron sus puertas" a Tefnajt antes de la invasión cushita.

Algunas divinidades asociadas a la zona se han documentado en fuentes escritas de diversa índole y en restos arqueológicos hallados en el lugar. En los momentos más antiguos figuran dioses como Nemty, Dunanuy, Anubis, o Igay. Horus de Hut-nesut, más adelante, tendrá un relevante papel en la llegada al trono de Horemheb, al reconocer en él al futuro faraón de Egipto. Por último, Osiris y Harsiese utilizan el epíteto "Señor de Hut-nesut" en monumentos ptolemaicos.

Se trata de una zona arqueológica poco explorada, aunque existen referencias a sus restos como consecuencia de visitas y trabajos de diferentes autores. Así, en 1835, John Gardner Wilkinson es el primero en mencionar el yacimiento comentando la presencia de restos de ladrillos y piedras y algunas cuevas rudimentarias ${ }^{1}$. Tres años después, Nestor L'Hôte destaca los restos de un templo, que desaparecerá poco después, y cita por primera vez la tumba de Pepianj-Jui, la más importante del lugar ${ }^{2}$. Mary Brodrick y A. Anderson Morton $^{3}$, publicaron en 1899 un trabajo sobre esta misma estructura funeraria. En 1907, los papirólogos Bernard P. Grenfell y Arthur S. Hunt ${ }^{4}$ localizan la estela de un personaje llamado Beba, del Reino Antiguo, en la que se citaba a Anubis, Señor de Hut-benu; excavaron también algunas tumbas del Reino Nuevo y de época ptolemaica, abandonando finalmente el lugar ante la imposibilidad de hallar papiros, debido a la acción destructora de los sebajim.

Tadeus Smolenski, es el responsable de los trabajos más intensos realizados en Sharuna hasta los años setenta del siglo pasado ${ }^{5}$. En 1907, el egiptólogo polaco hace la primera copia exhaustiva de los textos jeroglíficos de Pepianj-Jui, así como excavaciones arqueológicas que pusieron al descubierto 18 bloques procedentes de un templo ptolemaico en los que podían leerse los nombres de Ptolomeo I y Ptolomeo II.

Desde estos momentos, y salvo esporádicas visitas de egiptólogos como Hermann Ranke ${ }^{6}$, en 1913, y Jean Capart ${ }^{7}$, en 1927, el yacimiento no fue objeto de actuaciones científicas hasta 1976. En esa fecha, y debido a la proliferación de saqueos y robos diversos, el Servicio de

1. Wilkinson, 1843: 23.

2. L'Hôte, 1840: 31-35.

3. Brodrick y Morton, 1899.

4. Grenfell y Hunt, s.d.: 4.

5. Smolenski, 1907, 1908 y 1910.

6. Ranke, 1926: 1.

7. Capart y Werbrouk, 1927: 116-118. 
Antigüedades Egipcio restauró y cerró la tumba de Pepianj-Jui, además de realizar excavaciones durante tres campañas entre 1976 y 1981, dando como resultado el descubrimiento de numerosas tumbas, especialmente del Reino Antiguo ${ }^{8}$.

La historia más reciente de los trabajos arqueológicos en Sharuna se remonta al año 1984, fecha en la que el Instituto de Egiptología de la Universidad de Tübingen comenzó su intervención ${ }^{9}$. A lo largo de seis campañas, entre 1984 y 1989, Farouk Gomaà y Wolfgang Schenkel dirigieron las tareas de documentación planimétrica y epigráfica en las tumbas decoradas del Reino Antiguo descubiertas hasta entonces. Se hicieron también trabajos de excavación complementarios en el cementerio del Reino Antiguo y otros sectores de la necrópolis a fin de definir sus momentos de ocupación. El resultado parcial de estas tareas ha sido publicado en la obra Scharuna $\mathrm{I}^{10}$, dedicado a las tumbas del Reino Antiguo.

En 1991, tras diferentes sondeos efectuados en 1985, 1986 y 1989, se realizó una importante intervención en la zona denominada 'Izba, donde fueron descubiertos los primeros testimonios de hábitat faraónico del yacimiento. Los resultados muestran una ocupación que comienza a finales del Predinástico y se extiende sin interrupción hasta el Reino Medio ${ }^{11}$.

Entre los años 1994 y 2000, bajo la responsabilidad de Béatrice Huber, las tareas se centraron en el denominado Kom 5, en plena zona de cultivo, donde se presumía la ubicación de alguno de los templos citados por los investigadores previos. Aparecieron restos arquitectónicos de época ptolemaica, aunque reutilizados como material constructivo en un complejo basilical bizantino ${ }^{12}$. En este último se diferenciaron dos fases principales de construcción y uso: en la primera, la iglesia más antigua fue construida sobre una tumba de ladrillo considerada como el sepulcro de un santo, reconvirtiéndose en una cripta de accesible por una escalera. La segunda fase comportó la ampliación de la iglesia original. Se localizaron alrededor de mil enterramientos tanto en el interior del edificio como en un cementerio extendido en un radio de $200 \mathrm{~m}$.

Desde el año 2002, el proyecto se ha centrado en la excavación de un pequeño complejo monástico situado unos $800 \mathrm{~m}$ al este de las tierras de cultivo, a la altura de la necrópolis faraónica y la basílica. Se trata del yacimiento de Deir el-Qarabin, muy arrasado y afectado por expolios recientes, aunque se ha podido recuperar la práctica totalidad de su planta, identificándose estructuras de culto, un pequeño cementerio, zonas de hábitat y de realización de actividades económicas, y una torre de defensa ${ }^{13}$.

\section{La colaboración del Museu EgIPCi de BARCELONA}

A finales del año 2004, el Dr. Farouk Gomàa, sugirió la incorporación del Museu Egipci de Barcelona al proyecto Sharuna. En enero de 2005 , tras la visita al yacimiento y la valoración de sus posibilidades, la propuesta de

8. Para un resumen de los trabajos realizados por el Servicio de Antigüedades Egipcio, ver Schenkel y Gomaà, $2004:$ 39-41.

9. Un resumen y una bibliografía completa de los trabajos llevados a cabo hasta el año 1991 se encuentran en Schenkel y Gomaà, 2004: 42-45, notas 146-191.

10. Schenkel y Gomaà, 2004.

11. Gesterman et alii, 1992.

12. Huber, 1998 y Huber, 2004a.

13. Huber, 2004b. 
colaboración fue aceptada. Nuestra entidad asumiría la mayor parte de los gastos de financiación y pasaría a formar parte del equipo de trabajo encargado de los trabajos arqueológicos en la necrópolis principal. Paralelamente, otro grupo científico dirigido por Béatrice Huber, seguiría el estudio de la fase de ocupación bizantina, con la continuación de las excavaciones en Deir el-Qarabin. De este modo, se reanudó la actividad en la necrópolis de Sharuna, interrumpida desde 1989.

El sector elegido para la intervención se encontraba cerca del extremo oriental de la necrópolis principal. En esta zona eran apreciables varios recortes que a priori podían formar parte de una misma estructura (U20 en la nomenclatura alemana), aunque había serias dudas al respecto ya que sus dimensiones habrían superado con creces cualquiera de las tumbas de este período. Ya en la publicación Scharuna $\mathrm{I}^{14}$, la denominada tumba U20, gracias a los elementos visibles a causa de trabajos de excavación clandestinos, pudo describirse provisionalmente como una cámara con orientación E-O, con una estela falsa-puerta anepigráfica en la pared occidental y una entrada escalonada a pie de la misma; una sala en el extremo este del sector, cortada por un pozo ptolemaico, podía incluirse también en la misma estructura. Al norte de los recortes, varias perforaciones permitían el acceso a una enorme cámara (unos $15 \times 6 \mathrm{~m}$ ), prácticamente colmatada de escombros. Por tanto, se intuía la presencia de una gran estructura funeraria cuya correcta $y$ completa definición hacían necesaria una amplia intervención en extensión.

Con la excavación del nivel superficial, diversos pozos de saqueo y un gran paquete estratigráfico formado por sucesivas capas de paja y otros elementos vegetales alternadas o combinadas con capas de excrementos animales, fueron

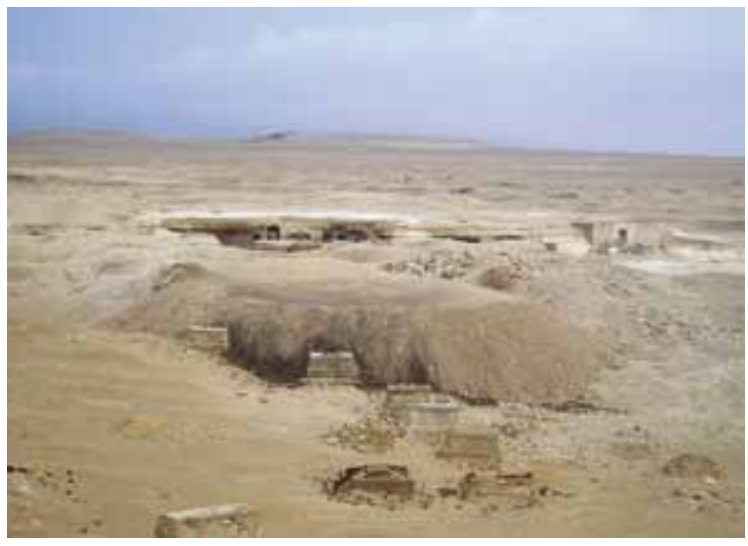

Figura 1. La tumba U20, junto a la conocida tumba de Pepianj-Jui

apareciendo las líneas de recorte que configuraban los componentes de la tumba: un gran patio rectangular de unos $16 \mathrm{~m}$ de longitud y $6 \mathrm{~m}$ de anchura, con una área porticada en el lado norte. En el centro de la pared septentrional del pórtico, una puerta conectaba con la enorme sala subterránea citada anteriormente, que según pudimos apreciar, parecía formar parte de una capilla de culto formada por dos ámbitos dispuestos en forma de " $T$ " invertida. A partir de aquí, las grandes proporciones del monumento obligaron a acotar el objetivo inicial a la excavación y la documentación del patio, dejando las zonas internas para más adelante.

Como resultado preliminar de la primera campaña, si bien quedan algunos puntos y detalles por esclarecer, se han podido establecer y definir las fases constructivas y los diferentes momentos de ocupación más significativos.

\section{Fase I}

Excavación en el substrato geológico calizo de una estructura funeraria formada por un patio rectangular, con camino de acceso definido por el sur y porticado en el norte (seis pilares;

14. Schenkel y Gomaà, 2004: 100. 
dos adosados a los extremos este y oeste y cuatro exentos). El pórtico sirve de antesala, al menos, a dos ámbitos dispuestos en forma de " $\mathrm{T}$ " invertida, donde supuestamente han de localizarse la cámara o cámaras sepulcrales principales. Se trata de una estructura muy regular, tanto en planta como en la ejecución técnica de sus componentes. En el patio y el pórtico, pudiendo formar parte del diseño inicial de la tumba, se encuentran varios hipogeos:

Hipogeo 1. Es el más elaborado. Se localiza en el extremo oeste del pórtico, a pie de una estela falsa-puerta anepigráfica; acceso por escalera y galería con orientación E-O hasta una sala rectangular (orientación N-S), con fosa central para la colocación del ataúd.
Hipogeos 5, 6, 7 y 8. Este último está inacabado. Lado noreste del pórtico; acceso por escalera y cámara en la propia prolongación de la galería de acceso (orientación S-N).

Hipogeos 3 y 10. En la mitad de los extremos este y oeste del patio. Acceso mediante escalera (orientación E-O el 3 y O-E el 10). El 3 es similar al 1, aunque sin fosa para ataúd; en el 10, el espacio correspondiente a la cámara sepulcral fue reutilizado durante la fase de ocupación bizantina como parte subterránea de una cocina, habiéndose perdido prácticamente cualquier indicio sobre la configuración original de la tumba.

En el acceso a los hipogeos 1 y 3, se localizaron estratos asociables a saqueos antiguos,

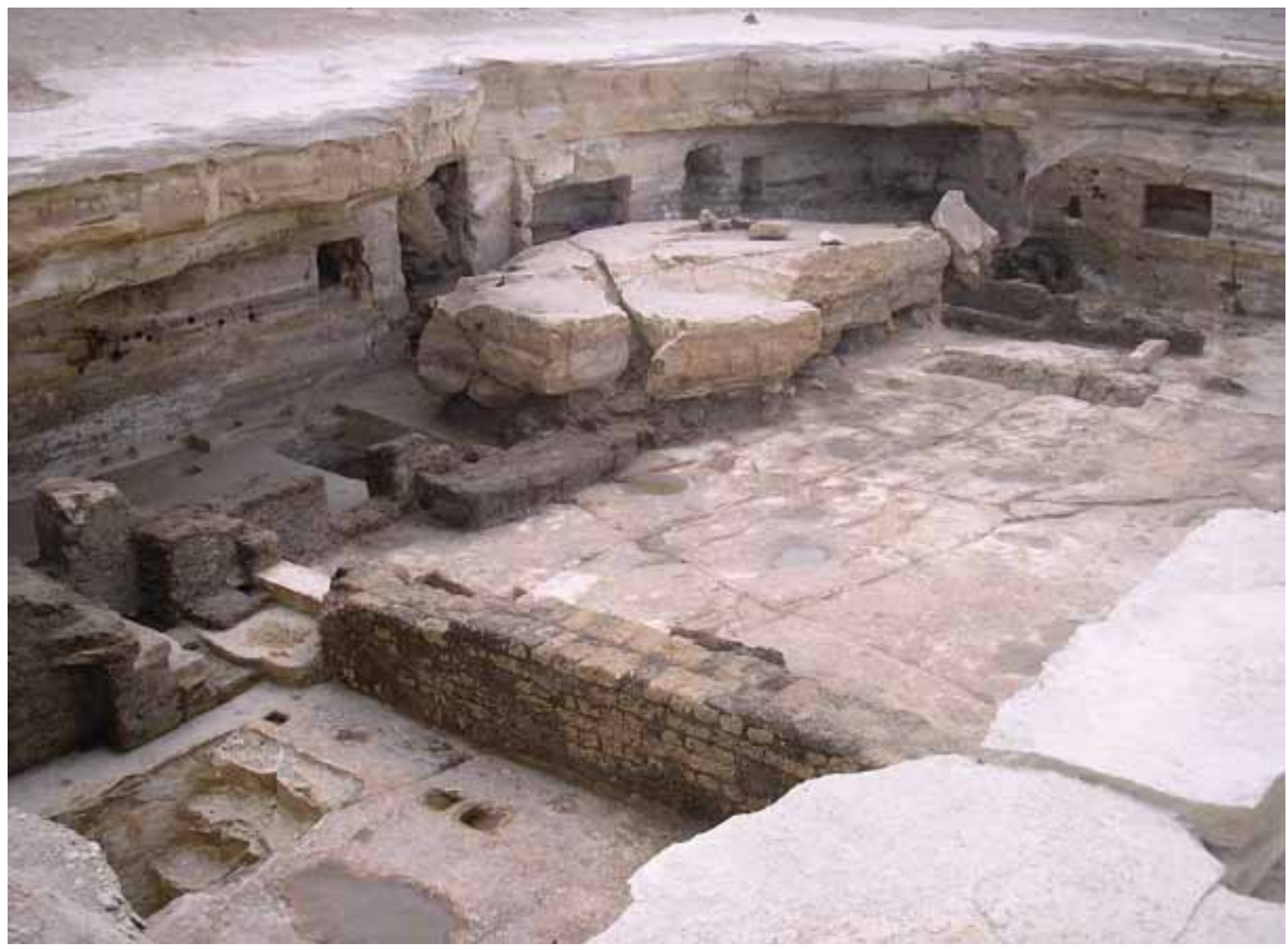

Figura 2. El patio y el pórtico de la tumba con el enorme bloque de piedra desprendido de la cornisa. En primer patio, la habitación oeste, y, al fondo, la cocina 
formados por arenas mezcladas con material cerámico de finales del Reino Antiguo, pequeños fragmentos de ataúd y restos humanos; en cualquier caso, como en todos los demás, los expolios más recientes habían alcanzado la cámara sepulcral. La fecha de construcción de U20 podría situarse durante la dinastía VI. Grosso modo, la forma de los hipogeos (en comparación con otros similares de este mismo yacimiento), la falsa-puerta y el material cerámico, así lo indican. Todavía no ha aparecido dato epigráfico alguno que permita identificar a los propietarios de esta tumba, aunque se ha de hacer constar que, a partir de sus dimensiones y calidad (es la más grande y regular, con diferencia, de las halladas en Sharuna para este período) podría haber pertenecido a uno de los personajes de mayor rango en la zona. Es también destacable la utilización de un elemento arquitectónico como el pórtico de una manera tan bien definida y ejecutada como en este caso; son pocas las tumbas de esta época con un dispositivo de presentación de esta categoría ${ }^{15}$. Como ya se ha comentado, esperamos que en la próxima campaña, con la excavación de las capillas de culto y las cámaras de enterramiento principales se puedan resolver algunas de estas interesantes cuestiones.

\section{Fase II}

Por tipología y ubicación, los hipogeos 4 y 9 podrían ser ligeramente posteriores a los de

[ 270 ] la Fase I. Se encuentran en el centro del patio y el acceso se realiza a través de un pozo que conduce a cámaras funerarias con orientación $\mathrm{S}-\mathrm{N}$ y N-S. Aunque afectados parcialmente por intrusiones y remociones posteriores, son los únicos en los que aparecieron restos humanos en conexión anatómica y elementos de equipamiento funerario. Así, en el primero de ellos se hallaron dos individuos adultos que fueron depositados en el interior de ataúdes rectangulares de madera, prácticamente desintegrados por la acción de las termitas. Los cuerpos se encontraban en decúbito lateral izquierdo con la cabeza situada en el norte, y la cara dirigida hacia el este. En el hipogeo 9, fueron detectados dos momentos de uso; en el primero, fue enterrado un individuo adulto de sexo masculino, cuyos restos fueron removidos para la instalación posterior de dos hombres adultos, que fueron colocados en sendos ataúdes de madera, en posición de decúbito supino con la cabeza situada en el lado norte. Entre los ataúdes y las paredes de la cámara sepulcral, a modo de equipamiento funerario fueron depositadas seis jarras ovoides características del final del Reino Antiguo.

\section{Fase III}

Insinuada de modo aislado por el hipogeo 2, tanto por el tipo de estructura, consistente en un acceso por pozo a dos pequeñas cámaras al norte y sur del fondo del mismo (disposición única en el conjunto), como por el tratamiento de los restos humanos asociables a su ocupante inicial (con restos claros de haber aplicado al difunto tratamientos de momificación) y la ubicación de la propia estructura (en el sector noroeste del pórtico). Es la única tumba en la que se han podido documentar, aunque desmontados por acciones de saqueo posterior, elementos de cierre entre el pozo y el acceso a las cámaras sepulcrales. Presenta serios problemas de adscripción cronológica, aunque podría tratarse de un hipogeo de la Fase I modificado posteriormente como resultado de diferentes fases de uso.

15. Una de las más logradas es la de Shedu, en Deshasha (Kanawati y Mc Farlane: 1993: 42-43 y lám. 40). De todos modos, hay yacimientos en los que la excavación y documentación completa de estos sectores de la tumba, aún no se han realizado. 


\section{Fase IV}

Tras lo que puede considerarse como un abandono prolongado de este sector de necrópolis, numerosas tumbas de pozo ptolemaicas fueron excavadas en las inmediaciones. La construcción de una de ellas, cuyo acceso ya aparece registrado en el plano general del yacimiento con el código U21, destruyó parcialmente el extremo oriental del pórtico. Durante esta campaña se vació su relleno (un potente estrato formado tras acciones de expolio modernas) y se alcanzó una gran cámara sepulcral, accesible desde el fondo de la pared meridional del pozo, también saqueada, y repleta de escombros, en la que eran visibles en primera instancia restos de la tapa y la caja de un gran sarcófago antropoide de caliza. La documentación completa de la misma será uno de los objetivos de la próxima campaña.

\section{Fase V}

Se trata del segundo período mejor representado del patio de U20, un momento de ocupación bizantina (aproximadamente entre los siglos V-VI d.C.), en el que patio y pórtico (y es posible que también la zona del interior de la tumba) fueron objeto de un proyecto general de actuación que la convirtió en un espacio de hábitat. En primer lugar, se recuperaron los niveles de circulación de la época del Reino Antiguo, a la vez que se realizaron intervenciones parciales como las detectadas en los hipogeos 4 y 9, que fueron parcialmente vaciados de sus rellenos, para volver a amortizarlos. En el caso del primero, éste fue colmatado con grandes bloques de piedra procedentes, quizás, de la limpieza del patio, mientras que la parte superior del pozo del hipogeo 9 estaba ocupada por un mazacote duro y compacto de barro y paja, restos de la argamasa utilizada para la fabricación de adobe; por último, la boca del pozo de acceso se regularizó con losas de piedra enrasadas con el nivel general del suelo del patio.

En el sector exterior de la tumba U20 se han podido individualizar, al menos, cuatro ámbitos diferentes: el ámbito 1 consiste en un patio central utilizado como área de distribución que cuenta con dos banquetas de adobe adosadas a los muros de los lados norte y oeste, y una tercera "banqueta" utilizada para la colocación de cinco contenedores cerámicos, en el lado este. La habitación oeste (ámbito 2), es accesible desde el patio por una puerta. Desconocemos su función exacta aunque la existencia de una fosa regular en el suelo en sentido N-S y diversas cavidades de sujeción sugieren una instalación industrial dedicada a las tareas textiles. En el umbral, fue una grata sorpresa descubrir la reutilización de diversos elementos de piedra de época ptolemaica para asentar el peldaño de entrada y para los propios peldaños, concretamente las dos mitades de una tapa de sarcófago antropoide y, sobre todo, un sillar de caliza con un oportuno programa iconográfico en el que destaca la mención a "Harsiese, Señor de Hut-nesut". Este espacio cuenta también con una escalera de acceso a un segundo nivel que parece formar parte de otra fase constructiva de la habitación, ya que el contrafuerte de la escalera amortiza diversas pinturas y grafitos coptos.

Más clara está la función del ámbito 3, utilizado como cocina. Conserva tres estructuras de combustión o calentamiento de alimentos, y dos compartimentos de adobe, uno de ellos conteniendo un mortero de piedra cuya mitad fue localizada in situ. Cuenta también con una sala subterránea realizada a partir de la adaptación de un hipogeo del Reino Antiguo. Se han hallado una cantidad importante de elementos utilizados como combustible (sarmientos de vid, vendas y momias de animal, y fragmentos de objetos en madera), así como sellos de ánfora para vino, 
esteras o una escoba. La cocina ocuparía todo el sector sudeste del patio, aunque la presencia de lo que parecen ser dos marcas de puerta adicionales, podría hacer pensar en la existencia de otro ámbito a partir de un muro de compartimentación en dirección E-O.

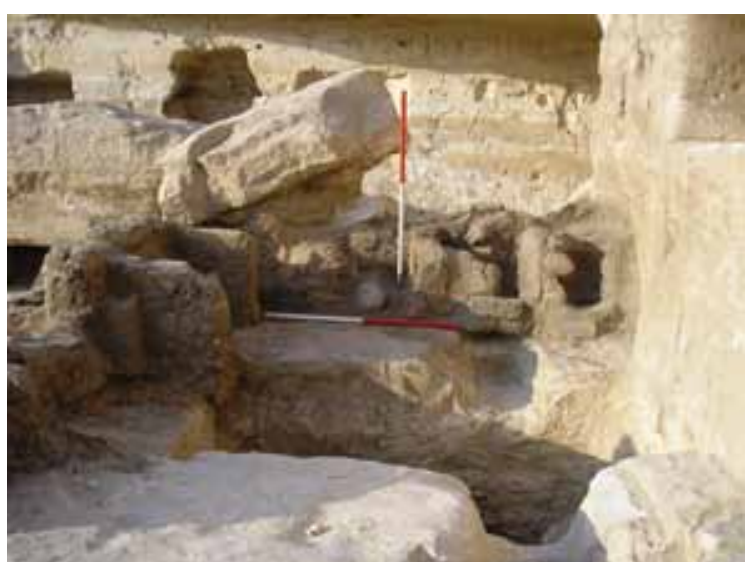

Figura 3. Hornos y compartimentos de la cocina copta. A la izquierda, un fragmento de cornisa caído

El ámbito 4 es accesible por una puerta situada en el sector oeste del patio. Podría haber ocupado la totalidad del pórtico, si bien también es probable que existiera un segundo espacio a partir de una hipotética compartimentación que estaría en la zona más afectada por la caída parcial de la cornisa del pórtico y las acciones de saqueo modernas. Las únicas estructuras bizantinas que definen la ocupación del sector se encuentran en el extremo este; consisten en una [272 ] pequeña banqueta, un habitáculo para la colocación de un contenedor cerámico y las reparaciones necesarias para cerrar esta zona tras la rotura producida por el recorte del pozo ptolemaico. Finalmente, en las paredes y suelo de este ámbito es donde se han conservado mayor cantidad de testimonios de ocupación consistentes en nichos, agujeros para la inserción de piezas de madera, pinturas o grafitos.

\section{Fases VI y VII}

El cese de la ocupación tardía bien pudo deberse al repentino desplome de una gran parte del techo del pórtico, que afectó de especial manera a su lado oriental y a la cocina. A partir del colapso de la cornisa, se asistió al derrumbe paulatino de los muros de adobe de los diferentes ámbitos, hasta formar un nivel bastante regular que acabaría por cubrir con mayor o menor potencia el sector exterior de U20. Sobre este estrato de derrumbe y abandono, en un momento dado, se aprovecharon los altos recortes del patio como refugio y abrigo estacional para el ganado, documentándose además algunas estructuras de combustión y otras con finalidad lúdica, que demuestran la presencia humana. Los innumerables estratos, consisten básicamente en una sucesión de capas de paja y otros elementos vegetales alternadas o combinadas con depósitos de excrementos animales.

\section{Fase VIII}

No podemos concluir la historia de la actividad en el sector sin redundar en la fuerte actividad excavadora de carácter no científico realizada en los tiempos más modernos. Estos "agujeros de saqueo" se documentan especialmente en los extremos este y oeste del pórtico, y a lo largo de los límites este y oeste del patio. Ya en su visita a Sharuna en 1927, Jean Capart escribió:

La colina está completamente acribillada de excavaciones; por todas partes hay pozos excavados en la roca...se ha de ver con que agilidad de mono los indígenas bajan atrevidamente al fondo de las tumbas ${ }^{16}$.

El grado de afectación a los restos arqueológicos de estas acciones, ininterrumpidas en buena parte del pasado siglo, ha sido muy 
grave, como hemos podido comprobar durante nuestra primera campaña.

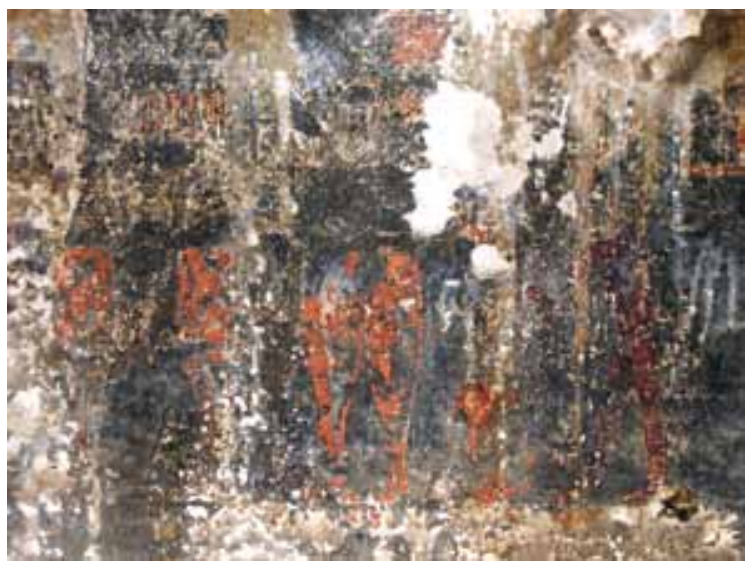

Figura 4. Un sector de las pinturas parietales de Gesa
Por último, hemos de destacar el minucioso trabajo de limpieza y conservación de pintura parietal realizado por Agustín Gamarra en una tumba de la necrópolis del Reino Antiguo perteneciente a un personaje llamado Gesa. El mal estado de conservación y las dificultades técnicas implícitas a una tarea de este tipo obligaron a posponer el trabajo de documentación en las campañas previas. Así, prácticamente de la nada, hemos asistido al renacimiento parcial de dos escenas pintadas completas relacionadas con la pesca y la preparación del pescado y el envasado de la cerveza. Esperamos presentarlas de una manera más elaborada en próximas comunicaciones de nuestros trabajos y tras los pertinentes retoques y comprobaciones que necesariamente hemos de realizar durante la campaña del año 2007.

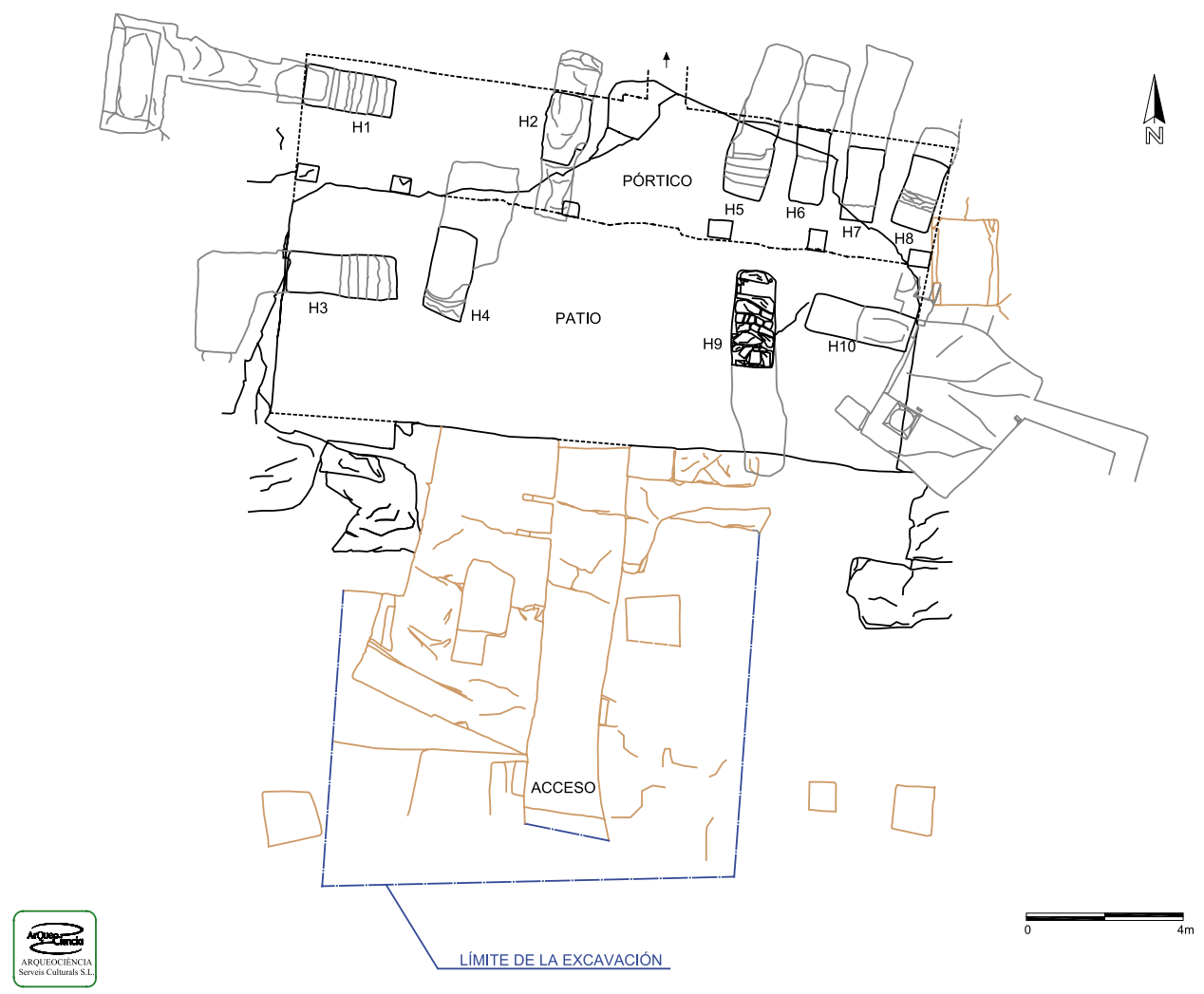

Figura 5. Planta general de la tumba U20, con la zona de acceso y los diferentes hipogeos documentados 


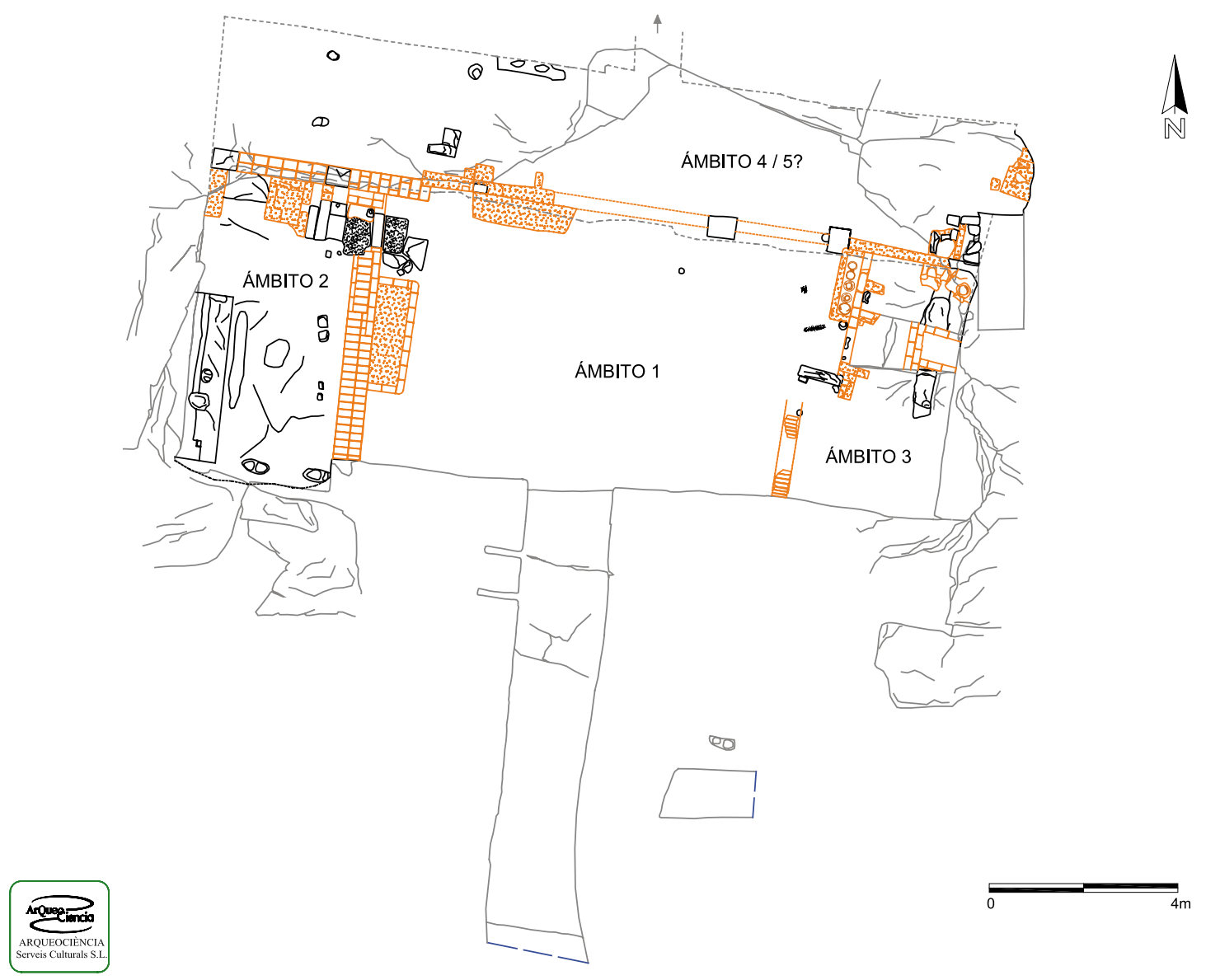

Figura 6. Planta del patio en la que se indican los diferentes ámbitos en los que se estructura la ocupación tardía del sector 


\section{Bibliografía}

Brodrick, M.; Morton, A.A.

1899 The Tomb of Pepi Ankh (Khua), near Sharona, PSBA 21: 26-33.

CAPARt, J.; Werbrouck, M.

1927 Impressions de voyage, $C d E$ 3: 103136.

Gesterman, L.; GomaÀ, F.; Heiligmann, B.; JÜRgENS, P.; SCHENKEL, W.

1992 Al-Kōm al-Ahmar/Šārūna 1991, GM 127: 89-111.

Grenfell, B.P.; Hunt, A.S.

s.d. Excavations at Hîbeh, Cynopolis and Oxyrhynchus, en Griffith, F. Ll. (dir.): Egypt Exploration Fund. Archaeological Report 1902-03, London: 4-9.

Huber, B.

1998 Al-Kom Al-Ahmar/Šaruna: découverte d'une ville de province, en Eyre, C.J. (ed.): Proceedings of the Seventh International Congress of Egyptologists, Leuven: 575-582.

2004a Die Grabkirche von Kom al-Ahmar bei Šaruna (Mittelägypten). Archäologie und Baugeschichte, en Immerzeel, M. y Van der Vliet (eds.): Coptic Studies on the Threshold of a new Millennium II, (OLA 133), Leuven: 1081-1103. 2004b Die Klosteranlage bei el-Kom el-Ahmar/ Saruna (Mittelägypten), BSAC 43: 45-64.

Kanawati, N.; Mc Farlane, A.

1993 Deshasha. The Tombs of Inti, Shedu and Others. (ACER 5). Sydney.

L'Hôte, N.

1840 Lettres écrites d'Égypte en 1838 et 1839 , contenant des observations sur divers monuments égyptiens nouvellement explorés et dessinés. Paris.

RANKe, $\mathrm{H}$.

1926 Koptische Friedhöfe bei Karâra und der Amontempel Scheschonks I. bei el Hibe. Berlin / Leipzig.

SCHENKel, W.; GomaÀ, F.

2004 Scharuna I. Mainz am Rhein, 2 vols.

SMOLENSKI, T.

1907 Le tombeau d'un prince de la VIe dynastie à Charouna, $A S A E$ 8: 149-153.

1908 Les vestiges d'un temple ptolémaïque à Komel-Ahmar près de Charouna, ASAE 9: 3-6.

1910 Nouveaux vestiges du temple de Kom-elAhmar près de Charouna, ASAE 10: 26-27.

WiLKINSON, SiR J.

1843 Modern Egypt and Thebes. London. 


\section{Trabajos de Egiptología Papers on Ancient Egypt}

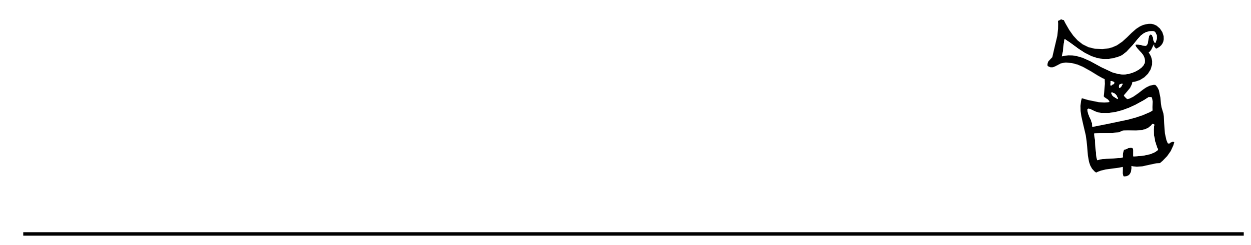

Número 5/1 2009 


\section{Actas \\ III Congreso Ibérico de Egiptología III Congresso Ibérico de Egiptologia}

Editores

Miguel Ángel Molinero Polo Covadonga Sevilla Cueva 


\title{
Editor
}

Miguel Ángel Molinero Polo

Universidad de La Laguna

\section{Consejo Editorial}

\author{
Antonio Pérez Largacha \\ Universidad de Castilla-La Mancha \\ José-R. Pérez-Accino \\ Birkbeck, Universidad de Londres \\ Covadonga Sevilla Cueva \\ Universidad Autónoma de Madrid
}

\section{Comité Científico}

Josep Cervelló i Autuori

Universitat Autònoma de Barcelona

$\mathrm{M}^{\mathrm{a}}$ José lópez Grande

Universidad Autónoma de Madrid

Josep Padró i Parcerisa

Universitat de Barcelona

$\mathrm{M}^{\mathrm{a}}$ Carmen Pérez Die

Museo Arqueológico Nacional, Madrid

Ester Pons Mellado

Museo Arqueológico Nacional, Madrid

José M. Serrano Delgado

Universidad de Sevilla

\section{Colaboradores Editoriales}

Linda Steynor

English editorial assistant

Hervé Mouriacoux

Assistant éditorial pour la langue française 
Trabajos de Egiptología está producida por Isfet. Egiptología e Historia c/ Blanco $1,2^{\circ}$

38400 Puerto de la Cruz

Tenerife-Islas Canarias

España

Maquetación: Proyecto Limón

(C) Autores de los artículos aparecidos

y Consejo Editorial de Trabajos de Egiptología - Papers on ancient Egypt

Depósito Legal: TF-2302-2009

ISSN: $1695-4750$

Imprime: Gráfica Los Majuelos, S.L.L.

imprenta@graficaslosmajuelos.com

Tfno.: 922311455 


\section{Comité Científico \\ III Congreso Ibérico de Egiptología III Congresso Ibérico de Egiptologia}

Miguel Á. Molinero Polo

Universidad de La Laguna

Presidente del Comité Organizador del III Congreso Ibérico de Egiptología

Miembro del Comité Organizador del I Encuentro de Egiptología

Josep Cervelló Autuori

Universitat Autònoma de Barcelona

Presidente del Comité Organizador del II Congreso Ibérico de Egiptologia

José Manuel Galán Allué

Consejo Superior de Investigaciones Cientificas

Director del Proyecto Djehuty, Luxor, Egipto

$\mathrm{M}^{\mathrm{a}}$ Helena Trindade Lopes

Universidad de Lisboa

Directora de la Misión Arqueológica Portuguesa en Menfis

Josep Padró i Parcerisa

Universitat de Barcelona

Director de la Misión Arqueológica de Oxirrinco

Antonio Pérez Largacha

Universidad de Castilla - La Mancha

Miembro del Comité Organizador del I Encuentro de Egiptología

José Ramón Pérez-Accino

Birkbeck College, University of London

Miembro del Comité Organizador del I Encuentro de Egiptología

$\mathrm{M}^{\mathrm{a}}$. Carmen Pérez Díe

Museo Arqueológico Nacional

Directora de la Misión Arqueológica Española en Heracleópolis Magna, Egipto

Covadonga Sevilla Cueva

Universidad Autónoma de Madrid

Miembro del Comité Organizador del I Encuentro de Egiptología 